\title{
¿MESIANISMO ALS OB EN WALTER BENJAMIN? ANTE LA NECESIDAD DE PENSAR EL CAMBIO SOCIAL EN EL CAPITALISMO INDUSTRIAL ${ }^{1}$
}

\author{
Lorena Acosta IgLesias \\ bttps://orcid.org/0000-0003-1694-4527 \\ Universidad Complutense de Madrid \\ bttp://dx.doi.org/10.15304/ag.39.2.6327
}

\section{Resumen}

La intención de este artículo será proponer una lectura tentativa del papel del mesianismo que sea acorde con la centralidad del concepto de experiencia y redención en Walter Benjamin y, al mismo tiempo, que sea capaz de dar con las tensiones teóricas propias de la maceración materialista de su pensamiento, así como la influencia inequívoca de problemas de cuño kantiano en la conformación de la atomización de la experiencia de la modernidad diagnosticada por Benjamin. Para ello, nos fijaremos en una de las últimas y más acabadas modulaciones del concepto de crítica inmanente en la figura del historiador dialéctico tal y como es abordada en El libro de los Pasajes.

Palabras clave: mesianismo, marxismo, Walter Benjamin, historiador dialéctico, crítica inmanente, experiencia.

Recibido: 07/10/2019. Aceptado: 18/02/2020.

${ }^{1}$ Este texto se ha escrito gracias a la subvención de una ayuda del Programa de Formación del Profesorado Universitario (FPU) y en el marco de los trabajos de investigación del proyecto del Ministerio de Economía, Industria y Competitividad FFI2017-83155-P «Naturaleza y Comunidad IV: El filósofo, la ciudad y el conflicto de las facultades, o la filosofía en la crisis de la humanidad europea del siglo xxI». Agradezco la lectura atenta de este artículo (y su paciencia), así como sus recomendaciones, a mis directores de tesis: José Luis Pardo Torío (UCM) y Pablo López Álvarez (UCM). También al investigador pre-doctoral y amigo Ignacio Planes (UCM). 


\begin{abstract}
The intention of this article will be to propose a tentative reading of the role of messianism that is consistent with the centrality of the concept of experience and redemption in Walter Benjamin and, at the same time, that is capable of finding the theoretical tensions typical of the materialistic maceration of his thought, as well the unequivocal influence of Kantian problem in shaping the atomization of the experience of modernity diagnosed by Benjamin. To do this, we will look at one of the latest and most complete modulations of the concept of immanent criticism in the figure of the dialectical historian as it is addressed in The Arcades Project.
\end{abstract}

Keywords: messianism, Marxism, Walter Benjamin, dialectical historian, immanent critique, experience.

«En la paradoja de la posibilidad de lo imposible se reunieron en Benjamin por última vez la mística y la Ilustración. Benjamin se deshizo del sueño sin traicionarlo ni convertirse en cómplice de aquello en que los filósofos siempre estuvieron de acuerdo: que no ha de ser»

TH. W. AdORNO²

La intención de este artículo será proponer una lectura tentativa del papel del mesianismo que sea acorde con la centralidad del concepto de experiencia y redención en Walter Benjamin y, al mismo tiempo, que sea capaz de dar con las tensiones teóricas propias de la maceración materialista de su pensamiento, sin caer, por el contrario, en un amasijo irracionalista de motivos teológicos y marxistas en el pensamiento benjaminiano. Éste, efectivamente, parece haber estado marcado por una recepción que tiende a propagar la ductilidad de su pensamiento ${ }^{3}$, aprovechando que bebió, ciertamente, de fuentes tan dispares como pueden ser, desde luego, el pensamiento judío a través de su amigo Scholem, así como cierto marxismo heterodoxo de Adorno y los demás colaboradores del Instituto de Investigación Social, pero también, como es conocido, del surrealismo, de la filosofía crítica (fundamentalmente Kant pero también el ámbito del idealismo alemán y cierto

${ }^{2}$ Th. W. Adorno, “Caracterización de Walter Benjamin (1950)” en Th. W. Adorno, Crítica de la cultura y sociedad Obra Completa 10/1, Madrid, Akal, 2008, p. 221.

${ }^{3}$ De este presupuesto parte, al igual que nosotros en el presente escrito, un libro cuya influencia en este artículo es abismal, no tanto por la letra del mismo; sino por su espíritu a la hora de exponer el pensamiento benjaminiano como cercano al de Th. W. Adorno, y en este sentido, más sistemático de lo que muchos querrían reconocer: E. Maura, Las teorías críticas de Walter Benjamin, Barcelona, Ediciones Bellaterra, 2013, pp. 15-31. 
romanticismo, además de un acercamiento a Marx mediado por la lectura lukácsiana), y, por último, una especie pseudocrítica literaria y estética que, de manera consabida, tiene por tótems a Baudelaire, Kafka, Walser, Kraus y Gide, entre otros.

Para ello, nos fijaremos en una de las últimas y más acabadas modulaciones del concepto de crítica inmanente en la figura del historiador dialéctico - tal y como es perfilada en El libro de los Pasajes - intentando vislumbrar los diferentes estratos de elementos marxistas y teológicos que, haciendo las veces de reactivos químicos, han sido capaces de dar con la fórmula más compleja del concepto de crítica inmanente en la obra benjaminiana.

\section{La tarea del historiador dialéctico: la crítica de la violencia es la filosofía de su historia}

Entenderemos la tarea del historiador dialéctico en el sentido de la construcción de un nuevo concepto de historia como constelación de peligros o campo de fuerzas ${ }^{4}$ que, en su seguimiento, el crítico trata de redimir de la trampa mortal del continuum homogéneo de la Historia con mayúsculas. Sin embargo, esta construcción no es en ningún sentido una reconstrucción, sino que en propiedad se trata de una destrucción que consigue una reconfiguración de los elementos en su propio estallido dentro del transcurso que los atrapa. De esta manera, es posible conectar la tarea del historiador dialéctico con el concepto de violencia divina, tal y como Benjamin lo expone en Crítica de la violencia. Allí Benjamin trata de dilucidar qué manifestación de la violencia sería capaz de responder a la «pregunta por la violencia inmediata pura que se vea capaz de poner coto a la violencia mítica» ${ }^{5}$. Esta violencia es aquella que Benjamin llama divina, en tanto que comparece como tal y, además, se opone a todo mito. Mientras que la violencia mítica instaura una relación jurídica que - nunca mejor dicho- de iure es violenta e inculpadora de todo lo vivo ${ }^{6}$, la violencia divina es redentora directamente con la mera vida, con lo creatural, "pues con la mera vida cesa todo dominio del derecho sobre los seres vivos» ${ }^{7}$. Su forma de presentación es

${ }^{4}$ «Toda circunstancia histórica que se expone dialécticamente, se polariza convirtiéndose en un campo de fuerzas [Kraftfeld] en el que tiene lugar el conflicto entre su protohistoria y su posthistoria» W. Benjamin, Obras V/I, Madrid, Akal, 2013, p. 756.

${ }^{5}$ W. Benjamin, Obras II/1, Madrid, Abada, 2007, pp. 201-202.

${ }^{6}$ Cfr. E. Maura, "Introducción” en W. Benjamin, Crítica de la violencia, Madrid, Biblioteca Nueva, 2010, p. 34.

${ }^{7}$ W. Benjamin, Obras II/1, p. 203. 
fulminante aunque incruenta: «Es propio de la salvación su sólida acometida, aparentemente brutal» ${ }^{8}$. Este 'aparentemente' se relaciona con la tarea del historiador dialéctico y asimismo con el concepto de historia natural, que en gran medida fue heredado del concepto de segunda naturaleza $a^{9}$ de Lukács:

La crítica de la violencia es la filosofía de su historia. Y es la "filosofía" de esta historia en la medida en que sólo la idea de su desenlace posibilita una actitud crítica separadora y decisiva de sus datos temporales..$^{10}$

Esta cita supone precisamente la prematura pista materialista que guiará nuestra lectura de la última etapa del pensamiento benjaminiano en conjugación con el mesianismo. Efectivamente, en contra de las lecturas más teologizantes de Benjamin, consideramos que, siguiendo en este punto a Eduardo Maura en su lúcida introducción a Crítica de la Violencia, en esta cita se puede leer entre líneas un momento en el que Benjamin ya empezaba a vislumbrar que la eterna repetición de emergencia y decadencia ${ }^{11}$ como formas simbólicas que atrapan un tiempo - esto es, su concepto de mito, el cual reproduce la Historia homogénea tributando al progreso- sólo puede comprenderse como "la otra cara de la moneda" del tiempo del eterno retorno de lo siempre igual que instaura la homogeneidad del tiempo abstracto del capital y que tiene su manifestación fenoménica en la moda. ${ }^{12}$

De ahí que la única manera de dar con un concepto nuevo de historia pase por una crítica del presente, en el sentido de una construcción que es, en el fondo, una destrucción ${ }^{13}$ de lo existente que se presenta como lo único

${ }^{8}$ W. Benjamin, Obras V/I, Madrid, Abada, 2013, pp. 222 y 223.

${ }^{9}$ Desde luego, hay que especificar aquí que el concepto de segunda naturaleza, originariamente, está desarrollado por Hegel quien, sin embargo, no fue leído tan exhaustivamente por Benjamin como sí hizo, por el contrario, con uno de los mejores hegelianos del S.XX como es Georg Lukács. Cfr. Th. W. Adorno, Sobre Walter Benjamin, Madrid, Taurus, 1995, pp. 16 y 17. Para consultar la lista de Verzeichnis der gelesenen Schriften remitimos a: W. Benjamin, Gesammelte Schriften - Band VII: 1, Frankfurt am Main, Suhrkamp, 1989, pp. 437-476.

${ }^{10}$ W. Benjamin, Crítica de la violencia, p. 120.

${ }^{11}$ E. Maura, "Introducción” en W. Benjamin, Crítica de la violencia, p. 25.

12 «La fe que se establece en el progreso - perfectibilidad inacabable, infinita tarea en lo moral- y la punzante representación del eterno retorno son pues complementarias. Son las imborrables antinomias frente a las que se impone el desarrollo del concepto dialéctico en su aplicación al tiempo histórico. Pues frente a él la representación del eterno retorno se convierte en ese "chato racionalismo" que mancha la creencia en el progreso, es decir, esa fe que pertenece al modo propio del pensamiento mítico de igual manera que le pertenece el eterno retorno como tal.» W. Benjamin, Obras V/1, p. 473.

${ }^{13}$ Cfr. "A los efectos del materialista histórico es imprescindible distinguir $-\mathrm{y}$ con el rigor más extremado- la construcción de un contenido histórico de eso que, habitual y 
posible. Por otra parte, esto mismo hace posible entender este nuevo concepto de historia como una forma de rememoración, en tanto que se trata de mostrar, a través del agotamiento cultural, una desnaturalización que hace convertir la reliquia en ser histórico y, por tanto, inconcluso. ${ }^{14}$

Efectivamente, el instante que irrumpe en el continuum de la Historia, entendida ésta como un tiempo vacío y homogéneo ${ }^{15}$, debe ser un instante impredecible que, cual relámpago, es capaz de trascender el marco de lo posible existente para hacer posible lo imposible. Por tanto, cierto es que se trata de un instante mesiánico, pero en tanto que, mediante una arqueología del origen de su ser social, lo sido, que no es pasado dentro de la linealidad de la Historia, se contrae en el tiempo cual mónada, esto es, como cápsulas de otro tiempo posible ${ }^{16} \mathrm{y}$, al quedar remanentes para que el historiador dialéctico pueda disponerlas en constelaciones de un nuevo sentido histórico, se produce ese Jetzt der Erkenntnisbarkeit [ahora de la cognoscibilidad], del cual la imagen dialéctica es su expresión y principio de movimiento. ${ }^{17}$

normalmente, se acostumbra a llamar "reconstrucción”. La "reconstrucción” empática es unívoca. "Construcción” es "destrucción”» W. Benjamin, Obras V/1, p. 756.

${ }^{14}$ Cfr. L. Acosta, "Walter Benjamin en torno a la constelación crítica: entre el veneno materialista y el mesianismo político", Mutatis mutandis: Revista Internacional de Filosofía, $\mathrm{n}^{\circ} 5,2015$, p. 32 .

${ }^{15}$ Nos referimos a un tiempo lineal independiente de las cosas que en él ocurre, sino posibilitador él mismo de las cosas que ocurren en él. Está determinado como cúmulo de ahoras en un presente continuo que, a su vez, se dirige tanto al pasado como al futuro. Este tiempo resulta heredero, al fin y al cabo, de la modernidad filosófica, y en concreto de la Estética transcendental de la Crítica de la razón pura de Kant como intentaremos mostrar más adelante, concretamente en el apartado tercero del presente artículo. Cfr. G. Deleuze, Kant y el tiempo, Buenos Aires, Cactus, 2008.

${ }^{16} \mathrm{Cfr}$. «El materialista histórico se acerca única y exclusivamente a un objeto histórico en cuanto se enfrenta a él como una mónada.»W. Benjamin, Obras I/2, Madrid, Abada, 2012, p. 316.

17 «Pues el índice histórico que les corresponde a las imágenes no nos dice tan sólo su pertenencia a un tiempo bien concreto; dice sobre todo que tan sólo en un tiempo concreto de su curso vienen a un punto de legibilidad. Y ese "venir a legibilidad" es un punto crítico concreto del movimiento dado en su interior. Porque todo presente se concreta en las imágenes que le son sincrónicas, y es que todo ahora es el ahora de una concreta cognoscibilidad. Allí, en ese ahora, la verdad aparece en tensión, hasta estallar: cargada de tiempo. [...] En consecuencia, no es que lo pasado venga a volcar su luz en lo presente, o lo presente sobre lo pasado, sino que la imagen es aquello en lo que lo sido viene a unirse como en relámpago al ahora para formar una constelación. Dicho con otras palabras: la imagen es dialéctica en suspenso. Dado que así como la relación del presente respecto del pasado es tan sólo continua, temporal, la de lo sido respecto del ahora es en cambio dialéctica: figurativa en su naturaleza, que no es de carácter temporal. Sólo las imágenes dialécticas son por lo tanto imágenes históricas —es decir, no arcaicas-. La imagen leída, esa que se halla situada en el ahora de su cognoscibilidad, lleva consigo el más alto grado el sello propio del momento 
En la crítica benjaminiana como salvación de lo muerto, es decir, de esa segunda naturaleza, se aúnan dos tiempos: por un lado, el tiempo del eterno retorno de lo siempre igual, propio de la moda, como manifestación sensible del tiempo homogéneo y vacío del historicismo - heredero éste a su vez de la modernidad-y, por otra parte, un tiempo sincrónico de lo sido en su ser cualitativo singular que cuaja en la imagen dialéctica. Ésta se rastrea en las huellas de los objetos que han salido del torbellino de la moda, la cual surge como nuevo patrón de medida del tiempo moderno vacío y homogéneo ${ }^{18}$, ya que, habiendo perdido su valor de uso, se alienan como cosa muerta en el formol del valor, se vacían y son saturados de subjetividad reificada.

Por tanto, con Benjamin, el tiempo ha de entenderse como coexistencia de tiempos. De ahí que el tiempo sincrónico saturado de sí mismo haga explotar, como si de un tiempo mesiánico se tratara, el tiempo continuo y homogéneo de la modernidad, cuyo infierno comenzó a ser patente en la modernidad capitalista. Este tiempo que irrumpe fracturando la línea recta del tiempo histórico, así como el de la cadena de producción, se traduce como mesiánico en tanto que es capaz de hacer posible lo imposible. Si se presenta como imposible, también en el pensamiento, es precisamente porque ese tiempo abstracto ha cristalizado en una pobreza de experiencia mediante la descomposición de los mundos perceptivos a través de la estetización de la vida cotidiana que hace realmente imposible pensar el cambio social.

\section{Pobreza de experiencia en el capitalismo fordista: piedra angular del pen- samiento benjaminiano}

A continuación, expondremos en qué sentido esta pobreza de experiencia, a través de una interpretación del escrito homónimo benjaminiano ${ }^{19}$,

crítico, es decir, el momento del peligro que hay en el fondo de cada lectura.» W. Benjamin, Obras V/1, pp. 743 y 744. [Énfasis nuestro].

${ }^{18}$ E. Maura, "Las modernas políticas del cuerpo: dialéctica entre cosa-a-la-venta y cosaa- la-moda en Walter Benjamin", La Torre del Virrey: revista de estudios culturales, $\mathrm{N}^{\circ}$ 5, 2008, p. 45

${ }^{19}$ Quisiera llamar aquí la atención sobre algunos lugares públicos donde José Luis Pardo, interlocutor ineludible de este artículo en lo tocante al concepto de pobreza de experiencia benjaminiano, ha tenido a bien dilucidar este concepto en relación con la modernidad capitalista y filosófica, y en cuyo diálogo insertamos las presentes reflexiones de este artículo: J. L. Pardo, Estudios del malestar. Políticas de la autenticidad en las sociedades contemporáneas, Barcelona, Anagrama, 2016, pp. 213-233 así como más directa y explícitamente en la siguiente conferencia: J. L. Pardo, "Pobreza y experiencia", Ciclo de conferencias NOON sobre cultura contemporánea. $2^{\circ}$. cuatrimestre 2013/2014, 3 de junio de 2014. Salón de Actos, de la E.T.S. Arquitectura, Sevilla. 
está relacionada con un tipo de atomismo de la experiencia que se puede leer a la luz del concepto de Industria cultural que acuñarán Adorno y Horkheimer, a mediados de los años cuarenta, en Dialéctica de la Ilustración, cuando el incipiente diagnóstico benjaminiano logrará mayor esplendor debido a la intensificación del capitalismo monopolista en los años inmediatamente posteriores a su muerte. ${ }^{20}$ Con ello, al mismo tiempo, veremos cómo dicho atomismo de la experiencia funciona a modo de quicio entre ambas concepciones de tiempo mencionadas, las cuales, como ya hemos comentado, se copertenecen ideológicamente: el tiempo lineal y homogéneo del progreso historicista y el tiempo del eterno retorno de la moda que implanta el capitalismo industrial. Esto nos permitirá plantear en términos de "als $o b$ " el papel del mesianismo declinado en esta última etapa del pensamiento benjaminiano, en tanto que supone, al mismo tiempo, una recuperación de planteamientos de cuño kantiano: efectivamente, el problema fundamental del pensamiento de Walter Benjamin es, en último término, responder al imperativo de salir de los límites de la experiencia transcendental -ideológicamente reproducida en las formas de sujeto en el caso benjaminianolo cual tiene, desde luego, fuertes ecos de la influencia de la filosofía crítica del pensador regiomontano.

De esta manera, indicaremos, en primer lugar, las notas que corresponden al concepto de Industria Cultural. Es preciso recordar que, en el momento en que Adorno y Horkheimer articularon dicho concepto en Dialéctica de la Ilustración, conllevaba una carga irónica que con el tiempo y el aumento de grado de subsunción real del capital ya ha perdido absolutamente para nosotros. En efecto, pretendía ser un concepto filosófico: se trata, en particular, de una ontología que pone en juego un determinado espacio-tiempo de producción cultural que, a su vez, es indiscernible del espacio-tiempo de la mercancía.

${ }^{20}$ El motivo de este ejercicio hermenéutico conjunto entre Pobreza de experiencia de Walter Benjamin y el capítulo de Industria cultural en Dialéctica de la Ilustración de Adorno y Horkheimer será doble: por un lado, evidenciar los continuos trasvases en ambos pensamientos, esto es, su posible re-traducción de un mismo problema, así como sincronizar ambos ritmos del pensamiento ante un problema que creemos común entre ambos pensadores, esto es, pensar lo imposible ante la homogeneización del tiempo y saturada a su vez de lo posible como lo nuevo-siempre-igual en la fase del capitalismo fordista. Por otro lado, nos permitirá comprender posteriormente el mesianismo als ob en Benjamin no como una ficción, tal y como reprochará Taubes a Adorno; sino presentar la rememoración como método micrológico en Benjamin como una verdadera «revolución copernicana en el horizonte de la moderna conciencia histórica». V. Rühle, "Transcendencia inmanente. La dimensión mesiánica de la experiencia histórica en Walter Benjamin", Revista de literatura y pensamiento, 2010, p. 51. 
Para ver qué entienden exactamente Adorno y Horkheimer por Industria Cultural, indicaremos algunos de los rasgos que la determinan: en primer lugar, para intentar diferenciar la industria cultural del fenómeno de la cultura de masas, diremos que ésta última —que ya se desarrolló en el s.XIX con exponentes como Baudelaire y Flaubert entre otros- consistía en la ampliación del espacio cultural al espacio de la mercancía, pero no su identificación o asimilación total. Esta ratio ya pertenece al paradigma de la Industria Cultural que empezó a desarrollarse a principios del s.xx con el cambio de fase del capitalismo que puso en marcha la forma de producción característica del fordismo ${ }^{21}$.

El tipo de ontología que rige la industria cultural funciona a través del principio unívoco de integración y asimilación de los productos culturales por parte de los monopolios como parte del proceso de concentración del capital y del control estatal en la administración de las grandes corporaciones, consiguiendo así, como efecto general a través de la administración total de la burocracia estatal, únicamente la perpetuación del statu quo. Sin embargo, no sólo consigue este efecto a través de la mera producción de objetos, sino que en ésta se lleva a cabo, como correlato, una reproducción de subjetividad abstracta, es decir, las masas son también, de hecho, su objeto, y así se comportan a través de la pérdida de autoconsciencia y autodeterminación mediante la funcionalización de la individualidad.

El modo de objetividad de la producción social de objetos a través de la división social del trabajo se ha convertido en esquematismo, al más puro estilo kantiano, como un a priori de la experiencia que relega al individuo al imperativo de la mera adaptación a lo ya existente como modo de autoconservación, siendo ésta una pervivencia de la individualidad como claudicación. Efectivamente, "para el consumidor no hay nada por clasificar que

21 «Es importante destacar que la idea de la muerte del sujeto individual se formula en conexión directa con un diagnóstico social determinado: las modificaciones en la naturaleza del capitalismo, y en concreto al tránsito entre capitalismo liberal y capitalismo monopolístico. [...] Más en concreto, y según se aprecia en los escritos de carácter sociológico de Adorno, las variaciones en del desarrollo del capitalismo permitirían comprender la actual situación del individuo, por cuanto arrastrarían: a) la superación, en virtud del proceso de concentración del capital, de los elementos definitorios del liberalismo clásico: esencialmente, la competencia, el mercado, el individualismo y el modelo de familia burguesa; y b) la convergencia del proceso de concentración de capital con un proceso de planificación económica y de control estatal de las funciones de producción y distribución de mercancías, en la forma de una interrelación de burocracia estatal, el aparato jurídico, la administración de las grandes corporaciones y las élites de los partidos.» P. López, "Ocaso del individuo, recuerdo de lo vivo. Sujeto y naturaleza en Adorno" en J. Muñoz, (Ed.) Melancolía y verdad. Invitación a la lectura de Th. W. Adorno, Madrid, Biblioteca Nueva, 2011, pp. 36 y 37. 
no venga ya anticipado en el esquematismo de la producción ${ }^{22}$. Por tanto, la libertad subjetiva se ve relegada a la mera elección formal entre objetos reproducidos por el mecanismo de la Industria Cultural. Éste produce sus objetos únicamente respondiendo a la forma mercancía, multiplicándose su producción en función de un tiempo cíclico que, en su retornar, muestra en apariencia como nuevo aquello que sólo acaece como lo último. En esencia, sin embargo, la forma mercancía tiene como máxima la evacuación de todo contenido en aras de invocar al tótem de la intercambiabilidad general, cuyo efecto consiste en relegar todo objeto a lo siempre igual.

Este sujeto que ha perdido la capacidad de experimentar sólo tiene como vía accesible una praxis cada vez más barbarizada -imitadora de lo ya existente-, incapaz de intentar recuperar siquiera el horizonte de posibilidad del cambio social. Esto es debido a que la Industria Cultural es capaz de producir una apariencia de libertad e igualdad y, así, desplaza el conflicto social como campo de fuerzas donde se pugna por la reconciliación del individuo con la totalidad social.

El sujeto-mónada cosificado es reflejo, que reproduce con su acción al consumir los objetos culturales, del esquema preestablecido —el principio unívoco y a su vez integrador que caracteriza a la Industria Cultural antes comentado - por el que se han producido dichos objetos — un modo de producción que, como nos clarifica Benjamin en su texto La obra de arte en la época de su reproductibilidad técnica, es ya siempre el modo de su reproducción-. Como es obvio, este cambio en el modo de producción acarrea grandes cambios en el propio objeto, pero también produce cambios en el modo en que la subjetividad se relaciona epistemológicamente con esos objetos, lo que hace que a su vez quede constituida ontológicamente de una determinada manera, modulando así un nuevo tipo de experiencia. Ésta se refiere a la que anteriormente hemos caracterizado por la imposibilidad de adquirir nuevas experiencias y que más tarde especificaremos en relación a ese nuevo tiempo que queda conformado como el espacio-tiempo de la mercancía.

«Para Benjamin la clave de la constitución del objeto no es el sujeto, sino la manera en que la objetividad, inseparable del sujeto, se constituye a través de él sin ser reducible a él, sin estar dentro de él, sin tampoco por ello trascenderlo». ${ }^{23}$ Por tanto, como dice Eduardo Maura, no se trata de

${ }^{22}$ Th. W. Adorno y M. Horkheimer, Dialéctica de la Ilustración Obra Completa 3, Madrid, Akal, 2007, p. 139.

${ }^{23}$ E. Maura, "Benjamin y el tiempo", Daimon. Revista internacional de Filosofía, $\mathrm{n}^{\circ}$ 57, 2012, p. 144. Quisiera destacar que este trabajo del profesor Eduardo Maura resulta de vital importancia para las investigaciones derivadas que en el presente artículo presentamos. 
concebir unilateralmente la clave del objeto en el sujeto, sino el modo por el cual la objetividad se constituye a través del sujeto sin poder posteriormente reducirse a él —que es de lo que se trataría cuando se intenta simplemente traducir la clave del objeto en el sujeto, es decir, intentar que el concepto dé la regla de construcción de los objetos ${ }^{24}$ - pero tampoco trascenderlo - como pretende el fenómeno del fetichismo de la mercancía-. Se trata, por tanto, de considerar los objetos en el modo de su aparición, y no en tanto que mera apariencia ${ }^{25}$, puesto que el modo de producción capitalista no remite a la conservación del valor de uso como esencia de la cosa, sino que remite a la intercambiabilidad del valor como condición de posibilidad del aparecer de la mercancía tal y como aparece, y, a su vez, conforma el espacio urbano: la apariencia ya es esencia.

Mediante la Industria Cultural, la cotidianidad deviene espectáculo ${ }^{26}$ para el individuo a través de la sobreexposición de objetos que salen al encuentro del sujeto, del que él es copartícipe en su producción y reproducción subjetiva, la cual radica en la exteriorización de sus acciones en el consumo de objetos, y que al mismo tiempo devienen interioridad falsa. El sujeto-mónada acepta esta falsa reconciliación con la realidad administrada que bloquea la posibilidad de nuevas experiencias y que se cierne sobre él como un destino, pues observa su vida como algo condenado a priori: la coparticipación del individuo en la reproducción del todo social está cifrada en su condena a priori por parte de dicha estructura social, que no se conforma con modificar las distintas potencialidades del sujeto a través de mecanismos de dominación, sino que consigue la entera autorrealización del sujeto a su imagen y semejanza.

Como si el sueño leibniziano se hubiera convertido en la realidad del proceso social: el individuo alienado acepta jovialmente en su reproducción subjetiva el reflejo perfecto del todo social, de tal modo que el propio sujeto se vuelve incapaz de adquirir experiencia genuina, o lo que es lo mismo, incapaz de abrir la posibilidad de entenderse como individuo no atomizado y liberarse de esta pobreza de experiencia - o la experiencia de la incapacidad de tener experiencias - para poder recuperar la libertad cualitativa,

${ }^{24}$ Opción que desestima inmediatamente Benjamin situado en una radical posición antisubjetivista, en la que la verdad es precisamente «la muerte de la intención» W. Benjamin, Obra I/1, Madrid: Abada, 2010, p. 231, y desde la cual acusa a Proust de querer encerrarse en la interioridad del sujeto a través de la mémorie involontaire.

${ }^{25}$ Cfr. E. Maura, "Benjamin y el tiempo", p. 144.

${ }^{26} \mathrm{O}$, dicho de otra manera: «Hoy, ideología significa: la sociedad como fenómeno» Th. W. Adorno, Crítica de la cultura y sociedad Obra Completa 10/1, Madrid, Akal, 2008, p. 21 
en orden a siquiera poder volver a pensar el modo de una existencia que no esté ya siempre condenada por este a priori de la experiencia, que en términos de dialéctica exterioridad-interioridad consigue, a través de la consecuente culpabilidad que conlleva cualquier espontaneidad del individuo en su ánimo de realizarse como tal, la perpetuación del todo falso debido a su reproducción subjetiva.

De esta manera, la moda otorga contenido al espacio-tiempo de la mercancía, el cual se comporta como forma a priori de la sensibilidad del sujeto, como hemos comentado con anterioridad. Con ello, el tiempo cíclico de la moda consiste en la producción colorida y, al mismo tiempo, sistemática de cadáveres. Estos objetos son devueltos a la vida enrolados en el tiempo como eterno retorno de lo mismo que vuelve como aparición en el presente. La novedad queda relegada al puesto de lo más actual, el cual no incluye la idea del telón de fondo de la tradición, como sí ocurría con la pretensión de novedad entendida al modo en que las revoluciones irrumpían en la Historia, sino que asume su simple destino a morir: la dicotomía entre naturaleza e historia ha quedado soldada y homogeneizada a través de la segunda naturaleza. La moda se comporta como el mejor ejemplo para entender, en contra del materialismo dialéctico, qué significa abastecer un aparato de producción sin querer, por ello, transformarlo. ${ }^{27}$ En la moda todo es asimilable, aprovechable y reutilizable. ${ }^{28}$ Los cadáveres, que vuelven a revivir en el presente eterno de la moda, son una suerte de Frankenstein: pastiches hechos de fragmentos arrancados de su continuidad histórica con el pasado.

\section{Genealogía de la modernidad capitalista: Kant y el problema del tiempo}

Se podrá advertir que el problema con el que se topa Benjamin al querer dar cuenta del espacio-tiempo de la mercancía como forma a priori de la sensibilidad, esto es, como formas propias de la percepción que conllevan la aparición de una diversidad empírica pero también pura, es en el fondo el clásico problema del tiempo. ${ }^{29}$

La liberación del tiempo de su retornar cíclico griego la encontraremos estandarizada, como es natural, en la gran estética transcendental de la

${ }^{27}$ Cfr. W. Benjamin, Obras II/1, p. 307

28 «El mundo... vive de sí mismo: sus excrementos son su alimento» Nietzsche, Obras completas, XIX, p. 371 (La voluntad de poder, libro cuarto) apud. W. Benjamin, Obras V/1, p. 216

${ }^{29}$ Cfr. E. Maura, "Benjamin y el tiempo", p. 142. 
Crítica de la razón pura de Kant. Obviamente, aunque tomemos a éste como el gran "emancipador" del tiempo, no quiere decir que sea el único que participó en la 'gran toma de la Bastilla' en la que se convirtió la modernidad respecto de la prisión del tiempo en el movimiento. Uno de los primeros que cortaron la cabeza al tiempo — cabeza que sería, evidentemente, del movimiento- en su expresión científica fue, como es de esperar, Newton. Sin embargo, fue Kant quien fue capaz de traducir en el sujeto y a la vez, de sistematizar en la experiencia de la modernidad, estos rudimentos científicos de los que se hacía cargo Newton, prácticamente de manera tentativa, en sus Principia.

Esta liberación del tiempo la cifraremos, con ayuda de Deleuze en Kant y el tiempo, en la famosa frase de Hamlet: "El tiempo está fuera de sus goznes". ${ }^{30}$ Aquí goznes quieren decir pivotes. Este pivote es la naturaleza en la cual el tiempo de los griegos se apoyaba para girar en su círculo. El tiempo se ha liberado de su subordinación a la naturaleza, esto es, del movimiento natural. Y, al liberarse de esta subordinación, ha devenido vacío y puro: sólo se ha desplegado en una parca línea recta. A partir de esta pura homogeneidad, ha de entenderse el espacio y el tiempo como recipientes en los que sólo en ellos pueden aparecer los objetos de toda experiencia posible, esto es, ha de entenderse espacio y tiempo ellos mismos como formas de aparición, pero sin que posean éstos una diversidad concreta - pues sería empírica- sino como formas de aparición de una diversidad pura, es decir, en tanto que siempre que haya aparición, será aparición de algo. Por tanto, aquí ha operado una inversión: ahora será el movimiento el que se subordine completamente al tiempo.

Esta es la imagen del mundo a la que, por otra parte, se refiere Lukács a propósito del fenómeno de la cosificación y las antinomias del pensamiento burgués en Historia y conciencia de clase ${ }^{31}$ como condición de posibilidad del trabajo humano indiferenciado. Efectivamente, para poder entender el trabajo humano como indiferenciado, esto es, que no esté subordinado al producto que realiza - como ocurre, por el contrario, en el trabajo cualificado del gremio-, ha tenido que operar ya la revolución copernicana de mano de Kant. Sólo a partir de ella cabe entender el tiempo como no subordinado a las cosas que pasaban en él, sino como posibilitador él mismo de que las cosas ocurran como tal en un momento determinado. Es decir, sólo porque el tiempo ha devenido pura línea recta abstracta, entendida como

\footnotetext{
${ }^{30}$ Cfr. G. Deleuze, Kant y el tiempo, p. 41.

${ }^{31}$ G. Lukács, Historia y conciencia de clase Vol. II, Barcelona, Orbis, 1985, pp. 7-78.
} 
indiferenciada de su propio contenido — pues en el fondo es posibilitador de cualquier diversidad empírica-, ha sido posible entender el trabajo humano como abstracto, medido en unidades de tiempo, que posibilitan el intercambio mercantil a través del valor de cambio. La modernidad ha sido la que ha puesto las bases conceptuales para entender el infierno en el que se ha convertido el modo de producción capitalista.

Por otro lado, a partir del cambio de fase del capitalismo liberal al fordista, tal y como hemos expuesto de modo somero a través del concepto de Industria Cultural, el embrujo de la mercancía comenzó a hacerse total, ya no existe ninguna atalaya posible para la crítica. ${ }^{32} \mathrm{~A}$ través de la estetización de la vida cotidiana, producida como mecanismo de compensación que fuera capaz de explorar nuevos mercados culturales, el valor de cambio empezó a devenir a su vez el único valor de uso: la ideología ya es ella misma realidad social material; la dicotomía entre valor de uso y valor de cambio se ha soldado de tal manera que el sujeto consume el propio valor de cambio, como podría ocurrir con la proliferación de distintas marcas de ropa, por ejemplo, en las que uno no consume el propio valor de uso, sino que consume la exclusividad y la personalidad que le otorga la propia marca, por lo que «quien presume de su superioridad se siente al mismo tiempo como uno más del equipo ${ }^{33} \mathrm{y}$, al mismo tiempo, el individuo se realiza a través de su claudicación.

La Industria Cultural consigue perpetuarse así como postergación de la falsa reconciliación con el sujeto, puesto que nunca se llega a una satisfacción palmaria de las necesidades, en tanto que lo que consume el sujeto no es el propio valor de uso, sino sólo su valor de cambio. Así, podemos observar cómo la teleología a partir de la cual se producen falsamente nuevas necesidades a través del consumo del valor de cambio consigue que la subjetividad abstracta —en su exteriorización en la pseudoelección de los productos culturales que produce la moda como lo nuevo siempre igualdevenga en una vacua interioridad a la que en apariencia es constitutiva un imperativo de expresividad de gozo y que, al mismo tiempo, resulta atomizada respecto de la limitación del universal, la Industria Cultural, y se sustrae constantemente en tanto que dichas falsas necesidades están producidas en él y por él.

${ }^{32}$ Cfr. J. A. Zamora, "Th. W. Adorno: crítica inmanente del capitalismo" en J. Muñoz, (Ed.), Melancolía y verdad. Invitación a la lectura de Th. W. Adorno, Madrid, Biblioteca Nueva, 2011, pp. 71-95.

${ }^{33}$ Th. W. Adorno, Crítica de la cultura y sociedad I, p. 10. 
Por tanto, preguntar por las condiciones de la aparición del objeto, tal como hace Benjamin, es en realidad, fijarse en lo que tiene de constituyente el sujeto respecto del objeto. Es decir, la realidad aparece como jeroglífico ${ }^{34}$ en tanto que desvelar el sentido de la aparición - que es lo mismo que señalar las condiciones de posibilidad de la misma- consiste en el fondo en intentar desatomizar la experiencia del sujeto que está atada a este a priori de la sensibilidad como pobreza de experiencia a través del sistema de percepción de un nuevo espacio-tiempo homogeneizado que ha constituido al sujeto y que es el propio, asimismo, de la mercancía. De la misma manera que con Kant, hablar de las formas precisamente a priori de la experiencia es lo que constituye el sentido de poder decir algo así como que se trata de las condiciones de toda experiencia posible, lo que implica a su vez el atomismo característico de esta pobreza de experiencia: lo que impide la utopía, el cambio social, no es lo existente, sino lo posible, en tanto que ni siquiera se presenta como pensable. ${ }^{35}$

34 «En efecto, es más fácil alcanzar al corazón de las cosas olvidadas para ir descifrando lo banal en su condición de jeroglífico [...]» (W. Benjamin, Obras V/1, p. 353). A su vez, Adorno decía sobre Benjamin: «Su insistencia disolvía lo indisoluble; Benjamin atrapaba la esencia precisamente donde la muralla de la mera facticidad cierra el paso a todo lo engañosamente esencial. Dicho con una fórmula, Benjamin quería escaparse de una lógica que envuelve lo particular con lo general o abstrae lo general de lo particular. Benjamin quería captar la esencia donde ésta no se puede ni destilar mediante una operación automática ni contemplar dudosamente: quería adivinarla metódicamente a partir de la configuración de los elementos ajenos al significado. El jeroglífico es el modelo de su filosofía» Th. W. Adorno, Crítica de la cultura y sociedad I, p. 210.

35 «Contra el parecer vulgar, en la dialéctica el momento retórico toma el partido del contenido. Al mediatizarlo con lo formal, lógico, la dialéctica trata de dominar el dilema entre la opción arbitraria y lo inesencialmente correcto. Pero se inclina hacia el contenido como hacia lo abierto, no decidido de antemano por el armazón: una protesta contra el mito. Mítico es lo perenne, que ha acabado por diluirse en la legalidad formal del pensamiento. Un conocimiento que quiere el contenido quiere la utopía. Ésta, la consciencia de la posibilidad, se adhiere a lo concreto en cuanto lo no deformado. Es lo posible, nunca lo inmediatamente real, lo que obstruye el paso a la utopía: por eso es por lo que en medio de lo existente aparece como abstracto. El color indeleble procede de lo que no es. Le sirve el pensamiento, un pedazo de la existencia que, aunque negativamente, alcanza a lo que no es. Sólo la más extrema lejanía sería la proximidad; la filosofía es el prisma que capta su color» Th. W. Adorno, Dialéctica negativa. Jerga de la autenticidad Obra Completa 6, Madrid, Akal, 2011, pp. 62 y 63. [Énfasis nuestro]. 


\section{Las aporías del mesianismo y la tercera antinomia de la razón pura: in- flujos del pensamiento benjaminiano hacia la conformación de la tarea del historiador dialéctico}

Así las cosas, quisiéramos adentrarnos brevemente en dos aporías inherentes al mesianismo judío ${ }^{36}$ respecto de la ambivalente relación entre elementos de conservación y la novedad para poder comprender su influencia en el concepto benjaminiano de historiador dialéctico - concepto que hemos venido desarrollando hasta ahora a través de la explicitación del método micrológico de crítica inmanente en Benjamin-: la primera aporía será la correspondiente al concepto de Creación y, la otra, al concepto de Redención, ambas diametralmente opuestas al concepto de Progreso.

Por lo que respecta al concepto de Creación, la aporía reside efectivamente en que el propio concepto remite tanto a la instauración de un orden dado invariante, como por otra parte a la venida de algo nuevo e imprevisto. En este sentido, existen dos modelos de mesianismo: por un lado, el primer modelo de creación es arqueológico, esto es, «el mundo es la expresión de un proyecto divino que se inscribe, desde el principio de las cosas, en la estructura secreta del Ser. La armonía de este proyecto ha sido destruida por una catástrofe primordial (que puede reproducirse en diferentes formas a lo largo de toda la historia). La aventura humana consistirá entonces en reparar algo que está roto, es decir, en recuperar, una y otra vez, el pasaje original de la verdad. Porque esa verdad existe, ha sido fijada desde un principio y permanece inmutable incluso cuando parece hurtarse por nosotros.» ${ }^{37}$. Por otro lado, está el modelo de la creación escatológico, en el cual «la verdad es un devenir, se va constituyendo día tras día a medida que

\footnotetext{
${ }^{36}$ Si bien tomaremos aquí como fuente principal para abordar este problema a Stéphane Mosès, queremos, sin embargo, recomendar acudir a la siguiente bibliografía que sería más que pertinente como panorámica orientativa complementaria en torno al judaísmo de Benjamin al acercamiento que aquí proponemos y que no podemos desarrollar por cuestiones de espacio: R. Navarrete, La psyché judeoalemana ante el derecho y el Estado: Walter Benjamin, Franz Rosenzweig, Revista de Filosofía, 44 (1), pp. 61-77, F. Albertini, "Historia, redención y mesianismo en Franz Rosenzweig y Walter Benjamin. Acerca de una interpretación política de La estrella de la redención”, en Á. E. Garrido Maturano, (Ed.), El nuevo pensamiento. Seis ensayos introductorios al pensamiento de Rosenzweig, Buenos Aires, Adriana Hidalgo, 2005, pp. 127-162, G. Scholem Walter Benjamin. Historia de una amistad, Barcelona, Península, 1987 y G. Scholem, Walter Benjamin y su ángel, Argentina, FCE, 2003. Agradezco todas estas referencias tan pertinentes y su inestimable ayuda al profesor Roberto Navarrete Alonso (UCM).

${ }^{37}$ S. Mosès, El ángel de la Historia: Rosenzweig, Benjamin y Scholem, Madrid, Cátedra, 1997, p. 164.
} 
se inventa lo nuevo. Incluso en este modelo escatológico, existe una estructura original de la verdad; pero sólo se trata de una forma puramente abstracta, sin contenido semántico identificable. [...] Para adquirir un sentido accesible al hombre, debe encarnarse en nuestro mundo empírico, es decir, desplegarse en el tiempo, fuente de renovación infinita, en el que revestirá formas siempre cambiantes. Al término ideal de este proceso, cuando haya conocido todas sus encarnaciones posibles, la verdad aparecerá en toda su universalidad pero también en toda su plenitud concreta.» ${ }^{38}$

La aporía es evidente en ambos modelos: por un lado, la realidad misma del tiempo que se manifiesta en el cambio no permite que el final de los tiempos sea idéntico a la Creación, pero la presencia de ese origen de la historia siempre limita la radicalidad de la novedad. «En este sentido, la fórmula más exacta de la filosofía de la historia que subyace en el mesianismo judío podría ser la siguiente: hay demasiadas limitaciones (o sentidos) en el origen de la historia para que sea absolutamente imprevisible; no hay suficientes, no obstante, para que esté absolutamente determinada» ${ }^{39}$.

La segunda aporía del mesianismo, como hemos anticipado, es respecto del concepto de Redención. Efectivamente, esta segunda aporía anida en torno a la contradicción entre continuidad o discontinuidad del proceso histórico, oscilando entre evolucionismo o anhelo de ruptura radical. De esta manera, si tomamos la Redención como un proceso histórico que se desarrolla en el tiempo, no podríamos decir que efectivamente trata de algo así como una revolución radical que haga implosionar las leyes naturales; pero, por otro lado, si tomamos la Redención como una irrupción transcendente en el mundo, necesariamente tendríamos que renunciar a su realidad histórica. Si echamos un vistazo a la $K r V$, podríamos decir que aquí nos encontramos, efectivamente, con la tercera antinomia de la razón pura, donde Kant plantea el tercer conflicto entre las ideas trascendentales. En efecto, si uno se toma en serio la analítica de los conceptos, donde se deduce trascendentalmente las categorías del entendimiento, y posteriormente la analítica de los principios, donde se deduce asimismo un canon que enseña al juicio a aplicar a los fenómenos aquellos conceptos del entendimiento que contienen a priori las condiciones relativas a las reglas, se llega a un concepto de naturaleza, del cual se ha derivado su lógica transcendental de las leyes físico-matemáticas newtonianas, donde no se puede concebir la causalidad por libertad y por tanto, es imposible introducir un nuevo orden de causalidad.

\footnotetext{
${ }^{38}$ S. Mosès, El ángel de la Historia: Rosenzweig, Benjamin y Scholem, p. 164.

${ }^{39}$ S. Mosès, El ángel de la Historia: Rosenzweig, Benjamin y Scholem, p. 165.
} 
Así ocurre de manera similar, efectivamente, en la paradoja inmanente al mesianismo que hemos intentado describir más arriba. ${ }^{40}$

Por tanto, la experiencia judía del tiempo no tiene nada que ver con el goce del instante presente del paganismo ni tampoco con la postergación de un más allá fuera del tiempo más propio del cristianismo, sino que se percibe como una aspiración de lo absolutamente nuevo en el seno mismo de tiempo que puede acaecer a cada momento histórico. Por otro lado, justamente en este punto podríamos encuadrar la tarea del historiador dialéctico dentro del pensamiento benjaminiano: se trata, efectivamente, de una creación destructora que, cual instante impredecible, rompe el continuum de la Historia con el fin de hacer posible lo imposible, esto es, el cambio social. La dialéctica entre lo nuevo y lo viejo que se puede cifrar en el tiempo de la moda — tal y como lo hemos abordado anteriormente- atomiza la experiencia de los individuos, relegándolos a lo nuevo siempre igual, esto es, promoviendo el statu quo y presentándose así el cambio social no sólo como imposible, sino de hecho como imaginable. De esta manera, creemos que podríamos cifrar el mesianismo como filosofía als ob dentro de esta etapa del pensamiento benjaminiano de cara a la conformación de la crítica inmanente hacia el final de su vida, esto es, fundamentalmente en El libro de los Pasajes. En un ejercicio de 'reverberación' de la influencia kantiana de Benjamin en la que nos adentraremos más adelante, podríamos decir que ese tiempo sincrónico que se condensa en lo ya sido como una mónada con el fin de quebrar el tiempo lineal y homogéneo, como si se tratara de la puerta pequeña por la cual ha de acontecer el Mesías, abre la posibilidad de poder pensar siquiera el cambio social, esto es, de dar con un concepto de experiencia no atomizada y, por lo tanto, hace posible la articulación de alguna manera del nexo entre teoría y praxis en un momento en que el embrujo de la mercancía se ha hecho total.

${ }^{40}$ Sin embargo, nosotros aquí no ahondaremos en el tipo de 'solución' que ofrece Kant a esta antinomia de la razón pura en el canon de la razón pura de la $\mathrm{KrV}$ dando el concepto de libertad transcendental, el cual exige «la independencia de esa voluntad misma (en lo que se refiere a la causalidad por la que inicia una serie de fenómenos) respecto de todas las causas determinantes del mundo sensible» I. Kant, Crítica de la razón pura, Madrid, Taurus, 2010, p. 629, ya que efectivamente, «la libertad transcendental parece oponerse a la ley de la naturaleza y, consiguientemente, a toda experiencia posible. Sigue, pues, constituyendo un problema. Ahora bien, éste no afecta a la razón en su uso práctico» I. Kant, Crítica de la razón pura, p. 629. Y, por lo tanto, deberíamos abordar el concepto de libertad práctica tal y como Kant lo hace en la Crítica de la razón práctica, y eso excede con mucho el propósito que aquí nos planteamos. 
Por tanto, se evidencia que la centralidad del concepto de experiencia en el pensamiento benjaminiano es deudora del planteamiento que ya en su juventud propuso en el texto llamado Sobre el programa de la filosofía venidera. Efectivamente, en este escrito Benjamin denuncia que el verdadero problema de la filosofía por venir es precisamente intentar salir, desde el presente, de los límites del concepto de experiencia kantiano, encerrado en la constricción a la que lo somete su concepto de naturaleza, extraído, por su parte, de la física matemática newtoniana. Sin embargo, si bien en su juventud, momento en el que escribe Sobre el programa de la filosofía venidera y también el Fragmento teológico-politico, Benjamin pensaba que la única forma de restituir la experiencia no atomizada era a través de la experiencia teológica como experiencia superior; más tarde, a través del concepto de historiador dialéctico y fundamentalmente expuesto en el Konvolut $\mathrm{N}$ de los Passagen-Werk, esto es, su carpeta metodológica, Benjamin trasladará la búsqueda de esa otra experiencia como anticipación de lo posible no atomizado — esto es, de la novedad como restitución de un pasado no reconocido en la linealidad de la Historia como tributo al progreso- en lo profano, en las huellas del origen social olvidadas a través de la gran influencia que tendrá en el pensamiento benjaminiano, no sólo el marxismo, sino también el surrealismo.

El problema de la teoría kantiana del conocimiento, como el de toda gran teoría del conocimiento, posee dos lados, y Kant solamente fue capaz de dar explicación válida a uno. Se trataba, primero, de la cuestión de la certeza del conocimiento, que es permanente; segundo, de la cuestión de la dignidad de una experiencia, la cual era efímera. Pues el interés filosófico universal se dirige al mismo tiempo a la validez temporal del conocimiento y a la certeza de una experiencia temporal, en la que se ve su objeto más cercano, cuando no el único. [...] Pero se trata precisamente de eso: de la noción de experiencia desnuda primitiva y obvia que a Kant, que compartía el horizonte de su época, le parecía ser la única dada e, incluso, la única posible. Y, sin embargo, esa experiencia era, tal como ya hemos indicado, una experiencia singular y temporalmente limitada; y, más allá de esta forma (que en cierto modo es propia para todos los tipos de experiencia), era una experiencia a la que, en sentido enfático, se podría llamar cosmovisión, que fue la propia de la Ilustración. [...] Y el tema de la filosofía venidera consistirá en mostrar en el sistema kantiano una típica que se halle en condiciones de hacer justicia a una experiencia superior ${ }^{41}$.

Ésta es, por tanto, la crítica de Benjamin a Kant en su juventud ${ }^{42}$. Kant pensó que toda experiencia posible estaba previamente dispuesta en unos

${ }^{41}$ W. Benjamin, Obras II/1, pp. 162, 163 y 164.

${ }^{42}$ Existe un estudio pormenorizado de esta cuestión, concretamente de la relación a través del concepto de tiempo como forma pura de la sensibilidad entre Benjamin y Kant a partir del texto Sobre el programa de una filosofía venidera en la siguiente referencia que 
esquemas transcendentales que la organizan y limitan. Como hemos intentado mostrar, esos mismos esquemas transcendentales constriñen a priori, a partir de la síntesis social de la reproducción capitalista, la espontaneidad del individuo y los límites de lo imaginable.

La pobreza de experiencia es heredera de Kant: esto ya supo verlo Benjamin en su juventud y se ha convertido en el problema central de su filosofía. En este sentido, Benjamin necesita presuponer la exigencia de hacer posible lo imposible: esto es, la exigencia de un vuelco sincrónico inmanente al propio tiempo vacío y homogéneo de la estética transcendental kantiana que, como hemos visto, obtiene su reproducción ideológica en el concepto de Historia moderno como tributo al progreso, así como en el tiempo tardomoderno capitalista tematizado por la moda, como dos caras de la misma moneda. Esto significa, al mismo tiempo, la necesidad de quebrar el atomismo de la experiencia reificada de la subjetividad abstracta con el fin de poder siquiera pensar otro concepto de experiencia, y poder articular así el nexo entre teoría y praxis sin postrar a ésta última a la propagación de mayor ofuscación ni barbarie.

\section{Conclusiones: ¿mesianismo als ob en Walter Benjamin? Ante la necesi- dad de pensar el cambio social en el capitalismo industrial}

En este sentido, consideramos que se puede interpretar en el pensamiento benjaminiano tardío - en el cual la consolidación de la influencia marxiana es evidente- el uso del mesianismo como exigencia del juicio de aquella experiencia atomizada para poder pensar siquiera el cambio social como posible, cuya posibilidad está trabada precisamente en su carácter de absoluta y radical novedad respecto del statu quo del orden capitalista. Por ello, entendemos que, en este punto, se podría trazar paralelismos con el propio planteamiento kantiano expuesto, ya no en $\mathrm{KrV}$, sino en las introducciones a la Crítica del juicio..$^{43}$ Efectivamente, allí Kant plantea la exigencia de un nuevo principio a priori, distinto de los principios categoriales

agradecemos enormemente al evaluador de este artículo: P. Fenves, "Pure Knowledge and the Continuity of the Experience: "On the Programm of the Coming Philosophy and Its Suplements" en P. Fenves, The messianic reduction. Walter Benjamin and the shape of time, Stanford, Stanford University Press, 2011, pp. 152-187.

${ }^{43}$ A continuación, estaremos siguiendo fundamentalmente la siguiente fuente: A.M. Andaluz, La finalidad de la naturaleza en Kant. Un estudio desde la Crítica del juicio, Salamanca, Publicaciones Universidad Pontificia Salamanca, 1990. Agradezco esta referencia al investigador pre-doctoral y amigo Jorge Mariano Burruezo Arcadio (UCM). 
del entendimiento, como condición de posibilidad del conocimiento de la naturaleza como sistema. De esta manera, Kant está poniendo en cuestión la posibilidad de un «sistema de experiencia según las leyes particulares de la experiencia.» ${ }^{44}$ Sin embargo, para Kant no hay garantía a priori de la posibilidad de dicho sistema, es decir, no se puede saber a priori si la naturaleza será apta para hacer posible un sistema semejante.

Los principios puros del entendimiento o principios categoriales, cuyo sistema se establece en la "Analítica de los principios» de la $K r V$, son leyes generales y, aunque tienen su origen en la espontaneidad de la facultad cognoscitiva, son leyes de la naturaleza tomada ésta como objeto de conocimiento en general para nosotros. Por tanto, sin estas leyes la naturaleza no podría ser pensada.

Sin embargo, Kant distingue entre la naturaleza en general, esto es, como objeto de experiencia posible y, por otro lado, la naturaleza determinada según leyes particulares. El primer concepto de naturaleza hace referencia a la interconexión de fenómenos bajo leyes que resulten necesarias para que éstos devengan objeto de nuestro conocimiento. En este primer sentido habla Kant de naturaleza en $\mathrm{KrV}$ y es al que se refiere Benjamin en el texto que anteriormente hemos mencionado: Sobre el programa de una una filosofía venidera. ${ }^{45}$ Sin embargo, el propio Kant se da cuenta de que este concepto de naturaleza no es suficiente: en la $K U$, Kant necesita hablar de la naturaleza como conjunto de formas particulares que se rigen por leyes empíricas. Efectivamente, hay una distinción entre la unidad a priori de la naturaleza y la naturaleza como un sistema según leyes empíricas. Por tanto, «la unidad de la naturaleza, según leyes generales, que el entendimiento posee a priori hace posible el conocimiento o la experiencia, en general; pero para la posibilidad de la experiencia particular hace falta además "un cierto orden de la naturaleza, en las reglas particulares de la misma" ${ }^{46}$. Ahora bien, de la unidad de la naturaleza como síntesis a priori según leyes transcendentales no se sigue la unidad de la naturaleza como sistema de leyes empíricas. Por

${ }^{44}$ I. Kant, Crítica del discernimiento, Madrid, Alianza, 2012, Introducción a la primera edición de 1790 [B V], p. 190.

${ }^{45}$ Para un desarrollo más pormenorizado de paralelismos entre Kant y Benjamin acudir a: F. Abadi, "Primera parte: conocimiento e historia: Kant, Cohen y la tarea infinita" en F. Abadi, Conocimiento y redención en la filosofía de Walter Benjamin, Buenos Aires, Miño y Dávila, 2014, pp. 53-106. Agradecemos esta referencia, así como su ayuda y apoyo, no sólo en este proyecto, sino en todos en los que nos embarcamos, al profesor Eduardo Maura (UCM).

${ }^{46}$ A. M. Andaluz, "La unidad de la naturaleza en las introducciones a la Crítica del juicio”, Cuadernos salmantinos de filosofía, n¹7, 1990, pp. 407 y 408. 
tanto, las leyes categoriales que fundamentan la unidad a priori de la naturaleza como objeto de conocimiento no son suficientes para garantizar un orden en la naturaleza según sus leyes empíricas; sin embargo, ese orden en la naturaleza según leyes empíricas es asimismo totalmente necesario como condición de posibilidad del conocimiento empírico.

En este sentido, se podría decir que Kant juzga como contingente dicha unidad de la naturaleza según sus leyes empíricas. Contingencia aquí se toma en relación con tercer postulado del pensar empírico de la "Analítica de los principios» de la $K r V$ : esto es, «aquello cuya interdependencia con lo real se halla determinado según condiciones universales de la experiencia es (existe como) necesario ${ }^{47}$

Efectivamente, para el entendimiento necesariamente tiene que aparecer como contingente la afinidad de las leyes particulares de la naturaleza con la unidad a priori de la misma, ya que en su legislación trascendental de la naturaleza, el entendimiento hace abstracción de esas leyes particulares.

De esta manera, esa afinidad ha de darse como contingente: está en la naturaleza misma del entendimiento humano, ya que éste es una facultad de conceptos, esto es, es un entendimiento discursivo (finito) bajo el cual no es determinado lo particular, sino que le deben ser contingentes las maneras múltiples en que lo particular puede ser dado en la naturaleza. Por tanto, si bien Kant en la $\mathrm{KrV}$ se ocupa de fundamentar mediante la deducción de las leyes categoriales a la naturaleza como objeto de experiencia posible, ésta no garantiza que la naturaleza en sus formas particulares sea capaz de concordar con nuestra expectativa de una experiencia real, concreta y efectiva, que sea asimismo sistemática. Esta posibilidad sólo se puede fundar bajo una presuposición del juicio, esto es, transcendental subjetivamente necesaria, en la afinidad entre la naturaleza según sus leyes particulares empíricas y la naturaleza según sus leyes generales como unidad a priori. En esto consiste, dicho someramente, el famoso als ob dentro del sistema kantiano y justo en este sentido, asimismo, pensamos que se podría trasladar esta cuestión al tratamiento del mesianismo por parte de Benjamin en la figura del historiador dialéctico.

A este respecto, hemos de llamar la atención sobre el hecho de que Adorno hablará específicamente del mesianismo als ob, concretamente en el famoso aforismo "Para terminar" de Mínima Moralia:

El único modo que le queda aún a la filosofía de responsabilizarse a la vista de la desesperación es intentar ver las cosas tal como aparecen desde la perspectiva de la

${ }^{47}$ I. Kant, Crítica de la razón pura, p. 241. 
redención. El conocimiento no tiene otra luz iluminadora del mundo que la que arroja la idea de la redención: todo lo demás se agota en reconstrucciones y se reduce a mera técnica. Es preciso fijar perspectivas en las que el mundo aparezca trastocado, enajenado, mostrando sus grietas y desgarros, menesteroso y deforme en el grado en que aparece bajo la luz mesiánica ${ }^{48}$.

Después del recorrido conjunto que hemos ensayado entre ambos autores, quisiéramos llamar la atención sobre la crítica que hará Taubes a esta "estetización" del mesianismo en Adorno y por qué creemos que se distancia del uso del mesianismo en el pensamiento benjaminiano. Esto ciertamente podría alcanzar para escribir otro artículo, por ello, simplemente daremos un par de notas al respecto, dado que dicha crítica tendrá lugar, en gran medida, en la lectura de Agamben en El tiempo que resta. Comentario a la carta de los romanos. ${ }^{49} \mathrm{Si}$ bien es cierto que el mesianismo en Adorno, al rechazar el contenido de la utopía como hipóstasis del pensamiento eidético-represivo, parte de la exigencia ficcional de lo ausente, del dolor como recurso epistemológico capaz implementar la crítica inmanente; en Benjamin, por el contrario, tal y como hemos pretendido exponer a lo largo de este artículo, no se negaría la realidad del mesianismo - factor fundamental, a todas luces, para la conformación de su pensamiento-, sino que su crítica inmanente del tiempo, cristalizada en la tarea del historiador dialéctico, "al sumergirse en los estratos profundos olvidados de la historia, no está interesado, de ninguna manera, en ponerla a disposición de la conciencia histórica. Más bien, pretende un giro radical en su visión, que en cada objeto histórico recordado ponga de manifiesto lo olvidado en él como su reverso constitutivo, para con ello cuestionar el propio ángulo de visión. [...] Con este giro, el motivo mesiánico de la salvación de todos los momentos del pasado descartados por la memoria no ha perdido nada de su insistencia. Pero este motivo ya no es cubierto por el nombre de "Dios", que remite a la instancia eminente de una transcendencia irrevocable y con ella a la eminencia de una experiencia superior. Más bien se trata de pensar la llamada insistente de los estratos de olvido inconscientes en el presente

${ }^{48}$ Th. W. Adorno, Mínima moralia. Reflexiones desde la vida dañada Obra Completa 4, Madrid, Akal, 2006, p. 257

${ }^{49} \mathrm{G}$. Agamben, El tiempo que resta. Comentario a la carta de los romanos, Madrid, Trotta, 2006, pp. 42- 50 y 135-142. Otros artículos que recomendamos como alternativa clarificadora a la lectura del mesianismo que planteamos aquí y que estarían más en la línea agambeniana: Galindo, A., "Mesianismo impolítico", Isegoría. Revista de Filosofía Moral y Política, n³9, 2008, pp. 239-250 y Muñoz, S., "La estructura del tiempo mesiánico en Benjamin, Agamben y Derrida. Hacia una temporalidad específicamente política”, Constelaciones. Revista de teoría crítica, nº10, 2018, pp. 236-274. 
como el ámbito espacio-temporal de una experiencia no condicionada, en la que las relaciones de exclusión e inclusión inconscientemente establecidas en una conciencia del ahora llegan a ser objeto de comprensión e interlocución, abriéndose así a una renovación sin condiciones previas.» ${ }^{50}$ De hecho, incluso podríamos decir que resulta llamativo que el propio Benjamin ya en la archiconocida primera tesis de Sobre el concepto de historia conjugue la importancia de la tensión bipolar, esto es, de coexistencia, correspondencia y constitución mutua entre materialismo histórico - que no dialéctico- - y teología mediante la imagen del jugador de ajedrez autómata. ${ }^{51}$

Benjamin, en definitiva, necesita pensar la contingencia como posible con el fin de poder romper el statu quo de la reproducción capitalista que presenta como natural los procesos sociales e históricos que han venido a dar con la conformación reificada de las formas de sociabilización o, dicho de otro modo, Benjamin necesita pensar «una concepción no instrumental de lo medial, de un medio emancipado de la teleología, sin fin, que delimita las fronteras de una experiencia de pasaje, pero en tanto experiencia soberana ${ }^{52}$.

Esta contingencia como siquiera pensable traería aquí y ahora, en el Jetztzeit, la pequeña puerta del Mesías por la cual poder pensar como posible algo absolutamente nuevo: el cambio social, salir de las ataduras del capital cuando el embrujo de la mercancía se ha hecho total. Por este motivo, su concepto de crítica inmanente se juega en dos tiempos: el tiempo sincrónico de la mónada que condensa lo ya sido, y que, como rememoración de un pasado inmemorial que no cabe en la Historia, quiebra el tiempo cronológico vacío, lineal y homogéneo de dicha Historia, cuya doblez es precisamente el tiempo cíclico del capital.

La rememoración en Benjamin, por tanto, sería ese doble giro copernicano, por el cual el rememorar, contra aquello que le reprochaba Horkhei$\mathrm{mer}^{53}$, a partir del tiempo sincrónico que abre como anamnesis del origen

${ }^{50}$ V. Rühle, “Transcendencia inmanente. La dimensión mesiánica de la experiencia histórica en Walter Benjamin”, Revista de literatura y pensamiento, 2010, p. 52-53.

${ }^{51}$ Cfr. Rühle, "Transcendencia inmanente. La dimensión mesiánica de la experiencia histórica en Walter Benjamin”, p. 43.

${ }^{52}$ L. I. García, "Para un materialismo del umbral. Walter Benjamin entre mito y razón”, Constelaciones. Revista de teoría crítica, no 4, diciembre 2012, pp. 209-210.

${ }^{53}$ Benjamin recibió una carta escrita por Horkheimer el 16 de marzo de 1937 en la que éste rezaba así: «La constatación de lo inconcluso es un proceder idealista si no incluye en sí misma lo concluso. La injusticia pasada ha sucedido y se encuentra conclusa y clausurada. Los matados a golpes son realmente unos muertos concretos y reales [...] Si tomamos en serio lo inconcluso, ello impone creer en la existencia del juicio final estrictamente.» Cfr. P. Lanceros, "Contratiempo. De un borrón de tinta en el papel secante" en J. Barja, y C. Rendueles, (Ed.), Mundo escrito. 13 derivas desde Walter Benjamin, Madrid, CBA, 2013. 
social trabado en las huellas de los objetos que han salido de la dinámica capitalista, consigue que el tiempo y el espacio ya no sean por sí mismos formas de aparición de la diversidad pura, sino que el recuerdo en tanto que proceso es capaz de tejer la posibilidad de un antes y un después cualitativo.

Lo que la ciencia deja "establecido" el rememorar puede cambiarlo. Éste en efecto puede convertir lo inconcluso (la dicha) en lo concluso, y a su vez lo concluso (el dolor) puede transformarlo en lo inconcluso. Cierto es que esto es Teología; pero en el curso del rememorar realizamos un tipo de experiencia que nos prohíbe comprender la Historia sobre un fundamento ateológico, aunque nunca debamos intentar escribirla empleando unos conceptos inmediatamente teológicos. ${ }^{54}$

\section{Bibliografía}

Abadi, F., Conocimiento y redención en la filosofía de Walter Benjamin, Buenos Aires, Miño y Dávila, 2014.

Acosta, L., "Walter Benjamin en torno a la constelación crítica: entre el veneno materialista y el mesianismo político", Mutatis mutandis: Revista Internacional de Filosofía, n 5, 2015, pp. 21-36.

Adorno, Th. W, Minima moralia. Reflexiones desde la vida dañada Obra Completa 4, Madrid, Akal, 2006.

Adorno, Th. W, Crítica de la cultura y sociedad I Obra Completa 10/1, Madrid, Akal, 2008.

Adorno, Th. W, Dialéctica negativa. Jerga de la autenticidad Obra Completa 6, Madrid, Akal, 2011.

Adorno, Th. W. y Horkheimer, M., Dialéctica de la Ilustración Obra Completa 3, Madrid, Akal, 2007.

Agamben, G., El tiempo que resta. Comentario a la carta de los romanos, Madrid, Trotta, 2006.

Albertini, F., "Historia, redención y mesianismo en Franz Rosenzweig y Walter Benjamin. Acerca de una interpretación política de La estrella de la redención", en Garrido Maturano, Á. E., (Ed.), El nuevo pensamiento. Seis ensayos introductorios al pensamiento de Rosenzweig, Buenos Aires, Adriana Hidalgo, 2005, pp. 127-162.

Andaluz, A. M., "La unidad de la naturaleza en las introducciones a la Crítica de juicio", Cuadernos salmantinos de filosofía, n¹7, 1990, pp. 405-413. https://doi.org/10.36576/summa.916

${ }^{54}$ W. Benjamin, Obras V/1, p. 758. [Cursiva nuestra]. 
Andaluz, A. M., La finalidad de la naturaleza en Kant. Un estudio desde la Crítica del juicio. Salamanca, Publicaciones Universidad Pontificia Salamanca, 1990.

Benjamin, W., Obras I/1, Madrid, Abada, 2006.

Benjamin, W., Obras II/1 Madrid, Abada, 2007.

Benjamin, W., Obras II/2, Madrid, Abada, 2009.

Benjamin, W., Obras IV/1, Madrid, Abada, 2010.

Benjamin, W., Crítica de la violencia, Madrid, Biblioteca Nueva, 2010.

Benjamin, W., Obras I/2, Madrid, Abada, 2012.

Benjamin, W., Obras V/1, Madrid, Abada, 2013.

Deleuze, G., Kant y el tiempo, Buenos aires, Cactus, 2008.

Fenves, P., The messianic reduction. Walter Benjamin and the shape of time, Stanford, Stanford University Press, 2011.

Galindo, A., "Mesianismo impolítico", Isegoría. Revista de Filosofía Moral y Política, n³9, 2008, pp. 239-250. https://doi.org/10.3989/isegoria.2008.i39.631

García, L. I., "Para un materialismo del umbral. Walter Benjamin entre mito y razón", Constelaciones. Revista de teoría crítica, $\mathrm{n}^{\circ} 4$, diciembre 2012, pp. 207-209.

Kant, I., Crítica de la razón pura, Madrid, Taurus, 2010.

Kant, I., Crítica del discernimiento, Madrid, Alianza, 2012.

Lanceros, P., "Contratiempo. De un borrón de tinta en el papel secante" en Barja, J., y Rendueles, C., (Ed.), Mundo escrito. 13 derivas desde Walter Benjamin, Madrid, CBA, 2013.

López, P., "Ocaso del individuo, recuerdo de lo vivo. Sujeto y naturaleza en Adorno" en J. Muñoz, (Ed.) Melancolía y verdad. Invitación a la lectura de Th. W. Adorno, Madrid, Biblioteca Nueva, 2011.

Lukács, G., Historia y conciencia de clase Vol. II, Barcelona, Orbis, 1985.

Maura, E., "Las modernas políticas del cuerpo: dialéctica entre cosa-a-laventa y cosa-a- la-moda en Walter Benjamin", La Torre del Virrey: revista de estudios culturales, $\mathrm{N}^{\circ}$. 5, 2008, pp. 43-46.

Maura, E., "Benjamin y el tiempo", Daimon. Revista internacional de Filosofía, n ${ }^{\circ}$ 57, 2012, pp. 137-149.

Maura, E., Las teorías criticas de Walter Benjamin, Barcelona, Ediciones Bellaterra, 2013

Mosès, S., El ángel de la Historia: Rosenzweig, Benjamin y Scholem, Madrid, Cátedra, 1997.

Muñoz, S., "La estructura del tiempo mesiánico en Benjamin, Agamben y Derrida. Hacia una temporalidad específicamente política”, Constelaciones. Revista de teoría crítica, nº10, 2018, pp. 236-274. 
Navarrete, R., "La psyché judeoalemana ante el derecho y el Estado: Walter Benjamin y Franz Rosenzweig", Revista de Filosofía, n44 (1), 2019, pp. 61-77. https://doi.org/10.5209/resf.64271

Pardo, J. L., Estudios del malestar. Políticas de la autenticidad en las sociedades contemporáneas, Barcelona, Anagrama, 2016.

Pardo, J. L., "Pobreza y experiencia", Ciclo de conferencias NOON sobre cultura contemporánea. $2^{\circ}$. cuatrimestre 2013/2014, 3 de junio de 2014. Salón de Actos, de la E.T.S. Arquitectura, Sevilla.

Rühle, V., "Transcendencia inmanente. La dimensión mesiánica de la experiencia histórica en Walter Benjamin", Revista de literatura y pensamiento, 2010, pp. 41-53.

Scholem, G., Walter Benjamin. Historia de una amistad, Barcelona, Península, 1987.

Scholem, G., "Walter Benjamin y su ángel” en: Walter Benjamin y su ángel, Argentina: FCE, 2003.

Zamora, J. A., "Th. W. Adorno: crítica inmanente del capitalismo" en $\mathrm{Mu}-$ ñoz, J., (Ed.), Melancolía y verdad. Invitación a la lectura de Th. W. Adorno, Madrid, Biblioteca Nueva, 2011. 